\title{
Spinal inclusion dermoid cyst in a patient with a treated myelocystocoele
}

\author{
HILARY BRYANT AND A. D. DAYAN \\ From the Department of Pathology, The Children's Hospital, and Wessex Regional \\ Neurological Centre, General Hospital, Southampton
}

Spinal epidermoid and dermoid tumours are rare neoplasms (Russell and Rubinstein, 1963). Recently, the epidermoid type of tumour has been reported relatively often in patients who have had multiple lumbar punctures (Blockey and Schorstein, 1961; Choremis, Economos, Papadatos, and Gargoulas, 1956), and has been thought to have arisen from implanted fragments of epidermis carried into the subarachnoid space by the lumbar puncture needle.

We have examined at necropsy a 3-month-old boy who had had a thoraco-lumbar myelocystocoele repaired shortly after birth and in whom a dermoid tumour had developed in the affected region.

\section{CASE REPORT}

A male child (General Hospital No. 221440) was the fourth child of healthy parents. His three sibs were normal.

He was born by Caesarean section because of a prolapsed arm, after 36 weeks of normal pregnancy. At birth (weight 2,880 g.) he was found to have a hyrocephalic head (circumference 15 in.), a left torticollis, and a myelocystocoele involving the lower thoracic and lumbar regions. He had a patulous anus and flaccid paralysis of both legs. On the same day, the myelocystocoele was repaired by freeing the margins of the dura at the sides of the defect, suturing them together, and closing the skin of the back with interrupted sutures. No skin was excised. Because of increasing hydrocephalus a Wade valve was inserted after five days. The child's progress was unsatisfactory because the hydrocephalus continued to increase slowly and the scar on the back became fluctuant. After one month the head circumference was $15 \frac{3}{4}$ in. and treatment was commenced with Diamox. Two months after birth his head measured $17 \mathrm{in}$. The valve was replaced and the head circumference decreased. He developed septicaemia and Staphylococcus albus was cultured from the blood. He was given Orbenin and ampicillin. He died suddenly four days later.

NECROPSY FINDINGS The body was that - of a hydrocephalic (head circumference $41 \mathrm{~cm}$.) male infant with the scar of a thoraco-lumbar myelocystocoele $6 \mathrm{~cm}$. long. In the viscera, the sole abnormality was organized blood clot in the right atrium partly surrounding the lower end of the plastic catheter of the Wade valve.
There was a typical Arnold-Chiari malformation. The cerebral hemispheres showed apparent micropolygyria and the lateral ventricles were greatly dilated. The corpora quadrigemina had grown backwards in a "cockscomb deformity'. There was stenosis of the aqueduct. From the inferior margin of the cerebellum, a tongue of abnormal tissue extended downwards for $5 \mathrm{~cm}$. dorsal to the cervical spinal cord which lay in a greatly dilated spinal canal.

Histological examination of the brain showed some marginal gliosis of the cortex and myelination compatible with the age of the child. The cerebellar tongue contained glial tissue, blood vessels, and fragments of choroid plexus.

The spinal column containing the cord was removed intact from about the fourth cervical vertebra to the sacrum. The skin and muscles of the lumbar region were left attached to the specimen. After fixation, it was decalcified and cut transversely into $1 \mathrm{~cm}$. thick slices from which histological sections were made.

In the cervical and upper thoracic regions the vertebrae and their arches appeared normal. At various levels, the cervical and upper thoracic spinal cord showed hydromyelia, forking of the central canal, and a syringomyeliclike cavity extending into both dorsal horns but it was not connected to the central canal in the sections examined. The latter cavity, about $2 \mathrm{~cm}$. long, was present only in the lower cervical region. It was partly lined by columnar cells which were not ciliated.

From the lower thoracic region to the sacrum, although the bodies of the vertebrae appeared normal, the neural arches had failed to develop properly. In this area, the spinal cord lay inside a dural sheath which was intact anteriorly, but, for a distance of about $6 \mathrm{~cm}$. in the lower thoracic-upper lumbar region, it was absent posteriorly. Replacing the dura dorsally was a cylindrical, keratinfilled dermoid cyst, some $5 \mathrm{~cm}$. long $\times 0.5 \mathrm{~cm}$. diameter, which was embedded in dense fibrous tissue. It extended anteriorly as far as the spinal cord which was somewhat flattened and compressed, and, posteriorly, it was surrounded by the subcutaneous tissues. The fibrous tissue around the cyst was continuous with connective tissue in the spinal subarachnoid space in this region. The cyst was composed of a basal stratum, several layers of cornifying cells, and large amounts of flaking keratin and hair follicles and sweat glands. There was little inflammatory infiltration anywhere. The spinal cord had been distorted by pressure and a fibrous band enlarging 


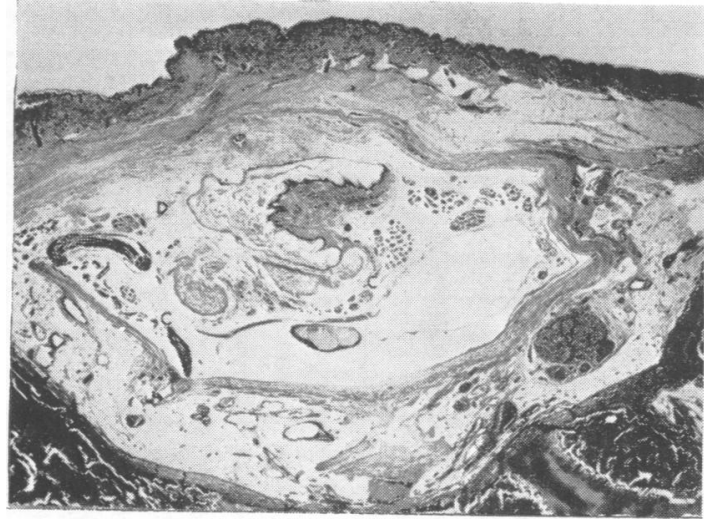

FIG. 1. Low-power view of spinal canal and skin of the back showing $C$-shaped dermoid cyst dorsal to remnant of spinal cord in lower thoracic region. Haemalum and eosin $\times 1.6$.

$(C=$ spinal cord; $D=$ dermoid cyst $)$.

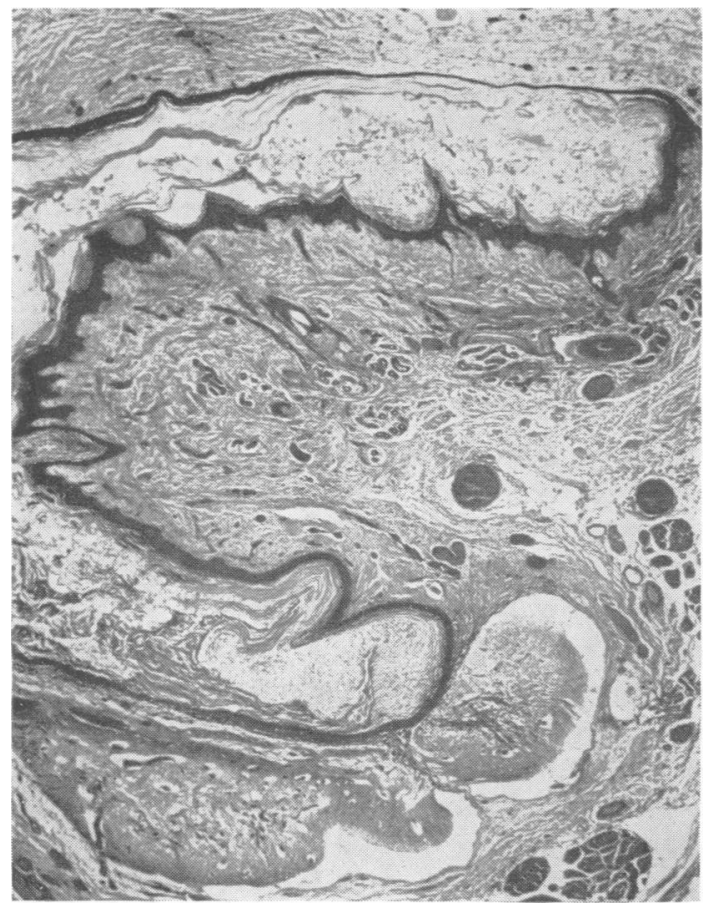

FIG. 2. Dermal appendages, including sweat glands and hair follicles, are attached to the cyst which is filled with flaky keratin. the posterior fissure so that the region of the posterior columns had become greatly attenuated.

\section{DISCUSSION}

Epidermoid and dermoid tumours affecting the central nervous system are usually considered to be due to neoplastic degeneration of heterotopic inclusions of ectoderm occurring in embryogenesis (List, 1941). Support for this hypothesis comes from their occurrence, usually in the midline or at other points of fusion of epithelial layers, and, often, the finding of a sinus running from the tumour to the overlying epidermal surface.

Recently, Choremis et al. (1956), Oeconomos and Caracalos (1957), Blockey and Schorstein (1961), and de Rougemont, François, Levy, Hermier, and Fournier (1962) have described young children with subarachnoid, extramedullary epidermoid cysts, sometimes multiple, of the lumbar region. In each case, the affected children have had multiple lumbar punctures (ranging from three to many) during the treatment of meningitis. Because the cysts were at the sites of the lumbar punctures, and because of their subarachnoid position and multiplicity, it was suggested that they arose from viable fragments of epidermis carried in by lumbar puncture needles.

In the present patient, the dermoid cyst could not have been derived from a congenital heterotopia because it arose at the site of a myelocystocoele. It seems likely that a fragment of epidermis was displaced during the repair operation and developed as a cyst at its eventual site of implantation. As such, it should be regarded as an implantation dermoid. It is surprising that the cyst grew so large in the 14 weeks of the patient's life. None of the other reported patients had developed symptoms in less than one to two years after the lumbar puncture. We cannot explain this finding, although it may be due in part to the very young age of our patient and and the high growth rate of his tissues, most other reports having been of older children aged 7 to 20 years. Perhaps also, the implant was larger than in the cases attributed to lumbar puncture.

\section{SUMMARY}

A male infant, suffering from the Arnold-Chiari malformation, died aged 14 weeks. He had a thoraco-lumbar myelocystocoele which had been repaired at birth.

At necropsy, a partly intradural, wholly extramedullary, dermoid cyst was found at the site of repair of the spinal cord defect. It is suggested that the cyst arose from epidermis implanted during the 
repair, and, as such, it is similar to the epidermoid cysts found after multiple lumbar punctures.

We are grateful to Dr. D. A. J. Williamson and Mr. T. Rowntree for permission to report this case.

\section{REFERENCES}

Blockey, N. J., and Schorstein, J. (1961). Intraspinal epidermoid tumours in the lumbar region of children. J. Bone Jt. Surg., 43B, 556-562.
Choremis, C., Economos, D., Papadatos, C., and Gargoulas, A. (1956). Intraspinal epidermoid tumours (cholesteatomes) in patients treated for tuberculous meningitis. Lancet, 2, 437-439.

List, C. F. (1941). Intraspinal epidermoids, dermoids, and dermal sinuses. Surg. Gynec. Obstet., 73, 525-538.

Oeconomos, D., and Caracalos, A. (1957). Cholestéatomes intrarachidiens multiples. Complication tardive d'injections intrarachidiennes pour méningite tuberculeuse de l'enfance. Rev. neurol., 97, 81-101.

de Rougemont, J., Francois, R., Levy, Mlle, Hermier, M., and Fournier, P. (1962). A propos d'une observation de tumeur épidermoide spinale de l'enfant d'origine traumatique. Pédiatrie, 17, 691-694.

Russell, D. S., and Rubinstein, L. J. (1963). Pathology of Tumours of the Central Nervous System, 2nd ed., p. 14. Arnold, London. 